\title{
Association of elevated lipoprotein(a) levels and coronary heart disease in NIDDM patients. Relationship with apolipoprotein(a) phenotypes
}

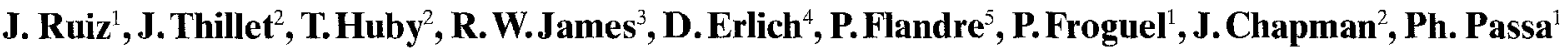 \\ ${ }^{1}$ Endocrinology Department, Saint-Louis Hospital, Paris, France \\ 2 INSERM U-321, La Pitié Hospital, Paris, France \\ ${ }^{3}$ Division de Diabétologie, University Hospital of Geneva, Switzerland \\ ${ }^{4}$ Biochemistry Department, Saint-Louis Hospital, Paris, France \\ ${ }^{5}$ INSERM U-194, La Pitié Hospital, Paris, France
}

\begin{abstract}
Summary Non-insulin-dependent diabetes mellitus (NIDDM) is a strong and independent risk factor for coronary heart disease. We assessed the potential relationship between plasma Lp(a) levels, apo(a) phenotypes and coronary heart disease in a population of NIDDM patients. Seventy-one patients with coronary heart disease, who previously have had transmural myocardial infarction, or significant stenosis on coronary angiography, or positive myocardial thallium scintigraphy, or in combination, were compared with 67 patients without coronary heart disease, who tested negatively upon either coronary angiography, myocardial thallium scintigraphy or a maximal exercise test. The prevalence of plasma $L p(a)$ levels elevated above the threshold for increased cardiovascular risk $(>0.30 \mathrm{~g} / \mathrm{l})$ was significantly higher $(p=0.005)$ in patients with coronary heart disease $(33.8 \%)$ compared to the control group $(13.4 \%)$. The relative risk (odds ratio) of coronary heart disease among patients with high L $\mathrm{p}(\mathrm{a})$ con-
\end{abstract}

centrations was 3.1 (95\% confidence interval, $1.31-$ $7.34 ; p=0.01$ ). The overall frequency distribution of apo(a) phenotypes differed significantly between the two groups $(p=0.043)$. However, the frequency of apo(a) isoforms of low apparent molecular mass $(\leq$ $700 \mathrm{kDa})$ was of borderline significance $(p=0.067)$ between patients with or without coronary heart disease (29.6\% and $16.4 \%$, respectively). In this Caucasian population of NIDDM patients, elevated Lp(a) levels were associated with coronary heart disease, an association which was partially accounted for by the higher frequency of apo(a) isoforms of small size. In multivariate analyses, elevated levels of $\mathrm{Lp}(\mathrm{a})$ were independently associated with coronary heart disease (odds ratio 3.48 , $p=0.0233)$. [Diabetologia (1994) 37:585-591]

Key words NIDDM, lipoprotein(a), apo(a) isoforms, coronary heart disease, lipids, lipoproteins, cardiovascular risk factors.
Non-insulin-dependent diabetes mellitus (NIDDM) is a strong and independent risk factor for cardiovascular and coronary heart disease mortality [1]. Established risk factors, including glucose intolerance, arterial hypertension, central obesity, hypercholesterolaemia or hypertriglyceridaemia, have been shown to contrib-

Received: 20 July 1993 and in revised form: 14 December 1993

Corresponding author: Dr. J. Ruiz, Clinique de Médecine 1, Hôpital Cantonal Universitaire de Genève, 24, rue Micheli-duCrest, CH-1211 Genève, Switzerland

Abbreviations: NIDDM, Non-insulin-dependent diabetes mellitus; IDDM, insulin-dependent diabetes mellitus; CHD, coronary heart disease; $\mathrm{Lp}(\mathrm{a})$, lipoprotein(a); apo(a), apolipoprotein(a); apoB, apolipoprotein B; HMGCoA reductase, hydroxymethylglutaryl coenzyme A reductase ute to the high prevalence of coronary heart disease in NIDDM $[2,3]$. The situation concerning $L p(a)$, a recently identified, independent cardiovascular risk factor, is less clear.

$\mathrm{Lp}(\mathrm{a})$ is a cholesterol-rich, LDL-like particle whose protein moiety contains apo(a) in addition to apoB. Apo(a) shows a strong sequence homology with plasminogen [4] and exhibits a genetic size polymorphism which arises from variation in the number of repetitive structures, termed "kringles" [5]. Indeed, the size of apo(a) isoforms is inversely related to plasma concentrations of $L p(a)$ [6]. Furthermore, the apo(a) phenotype determines at least $40 \%$ of the inter-individual variation in plasma $\mathrm{Lp}(\mathrm{a})$ level [7].

It has been established that high plasma levels of $\mathrm{Lp}(\mathrm{a})$, as well as apo(a) phenotypes of low molecular 
mass, are major risk factors for coronary heart disease among Caucasian and non-Caucasian populations which differ markedly in coronary heart disease prevalence and cardiovascular risk factor profiles [8-11]. However, not only is there a paucity of data on the potential contribution of $\mathrm{Lp}(\mathrm{a})$ to premature cardiovascular disease in NIDDM, but in addition, this question remains controversial. The majority of the studies reported to date have found no difference in $\mathrm{Lp}(\mathrm{a})$ levels and in the distribution of apo(a) phenotypes between NIDDM patients and non-diabetic subjects [12, 13]. Moreover, it remains to be established whether Lp(a) concentration represents a cardiovascular risk factor in NIDDM patients. Two previous studies provided negative results $[14,15]$, but a recent case-control study suggested that $\mathrm{Lp}(\mathrm{a})$ was an independent cardiovascular risk factor in NIDDM patients [16]. These contrasting findings may result from the small number of subjects studied, coupled to the lack of statistical power and above all, to the limitation that "control" groups may not have been properly evaluated for asymptomatic coronary heart disease. Indeed, the high frequency of silent myocardial ischaemia in diabetes [17] might lead to underestimation of the true prevalence of coronary heart disease in the "control" groups when diagnosis was effected either by clinical examination, or by a resting electrocardiogram, or both. Non-invasive investigations such as exercise electrocardiography or thallium myocardial scintigraphy are more sensitive in evaluating coronary heart disease in such patients $[18,19]$. Given the conflicting data concerning links between $\mathrm{Lp}(\mathrm{a})$ and coronary heart disease in NIDDM subjects, the aim of the present study was to assess the relationship between $\mathrm{Lp}(\mathrm{a})$ levels, apo(a) phenotypes and coronary heart disease in a Caucasian population of NIDDM patients in whom the coronary circulation had been extensively evaluated.

\section{Subjects and methods}

\section{Subjects}

Subjects in the present study were 138 consecutive NIDDM Caucasian patients ( 107 men and 31 women), who routinely attended a tertiary referral center between 1 June 1992 and 28 February 1993 and who either had evidence of coronary heart disease or were free of coronary heart disease. All the diabetic patients included in this study fulfilled World Health Organisation criteria for NIDDM [20]. Patients who agreed to participate in the study gave their informed written consent. The study was approved by the Ethics Committee of the Centre Hospitalo-Universitaire Lariboisière-Saint-Louis. The patients were classified into two groups. The first group consisted of patients with coronary heart disease $\left(\mathrm{CHD}^{+} ; n=71\right.$ ), and was composed of 31 patients with previously documented transmural myocardial infarction, 35 patients with significant stenoses or a single stenosis greater than $70 \%$ upon coronary angiography, four patients with positive dipyridamole myocardial thallium 201 scintigraphy and one patient who presented with a positive maximal exercise test. The second group consisted of 67 patients without coronary heart disease (CHD-), and was composed of 16 patients with no significant stenosis upon coronary angiography, 45 patients whose dipyridamole myocardial thallium scintigraphy test was negative and six patients who had a negative maximal exercise test. Exclusion criteria included renal insufficiency (serum creatinine $\geq$ $130 \mu \mathrm{mol} / \mathrm{l}$ ), drug or alcohol abuse, an inflammatory state (sedimentation rate $\geq 20 \mathrm{~mm} / \mathrm{h}$ ), a recent myocardial infarction ( $<3$ months), hepatic disease or neoplasia.

\section{Methods}

All examinations were performed at 08.00 hours after an overnight fast. The following clinical data were recorded by the same physician: height, weight, and blood pressure measured after 10 min at rest on the right arm using a mercury sphygmomanometer. Systolic and diastolic blood pressure were recorded to the nearest $2 \mathrm{~mm} \mathrm{Hg}$ at the first and fifth Korotkoff sounds. Body mass index was calculated as weight/height ${ }^{2}\left(\mathrm{~kg} / \mathrm{m}^{2}\right)$. Smoking habits were recorded. Smokers were defined as subjects who regularly smoked more than one cigarette per day, whereas ex-smokers were subjects who had regularly smoked more than one cigarette per day but who had stopped for at least 3 months before the examination; all other subjects were classified as non-smokers. A family history of coronary heart disease was defined as the clinical onset of coronary heart disease in any first degree relative parent or sibling before the age of 60 years. Arterial hypertension was diagnosed according to World Health Organisation criteria ( $\geq 160 / 95 \mathrm{~mm} \mathrm{Hg}$ ). Microalbuminuria was defined as an urinary albumin excretion rate between 30 and $300 \mathrm{mg} / 24 \mathrm{~h}$ and macroalbuminuria by an urinary albumin excretion rate of more than $300 \mathrm{mg} / 24 \mathrm{~h}$ for at least two consecutive $24 \mathrm{~h}$ urine samples; the expressed results were the mean of two determinations. Urinary albumin concentration was determined by an immunonephelometric method (Behring, Marburg, Germany). Venous blood samples were drawn after an overnight fast. $\mathrm{HbA}_{1 \mathrm{c}}$ was determined by HPLC (DIAMAT Analyser; Bio-Rad, Calif., USA); the normal range of $\mathrm{HbA}_{1 \mathrm{c}}$ in our laboratory is $4.0-6.0 \%$. Serum cholesterol was measured using CHOP-PAP reagents and triglycerides by an enzymatic method with reagents from Boehringer-Mannheim GmbH (Mannheim, Germany). Serum HDL-cholesterol was estimated enzymatically (Boehringer-Mannheim $\mathrm{GmbH}$ ), apoB being initially precipitated with phosphotungstate $/ \mathrm{MgCl}_{2}$. The quantitation of apo $\mathrm{A} 1$ and $\mathrm{apoB}$ in whole plasma was performed using commercial antibodies (Behring). Plasma creatinine concentration was assayed by the kinetic method of Jaffe. Lp(a) concentrations were measured in plasma samples stored at $-30^{\circ} \mathrm{C}$ for up to 2 months, using an ELISA method [21]. This assay was developed with two polyclonal antibodies, both prepared in sheep. An anti-human apo(a) antibody [22] was used as the "capture" antibody and a peroxidase-conjugated, anti-human apoB100 antibody as the detecting antibody. Intra- and inter-coefficients of variation for this ELISA assay were $1 \%$ and $2.6 \%$, respectively. Apo(a) phenotyping was determined according to Kamboh et al. [23] with minor modifications. In particular, apo(a) bands were revealed by use of a chemiluminescent substrate of alkaline phosphatase (AMPPD) [24]. This sensitive method allowed the detection of isoforms present at low concentration and thus the number of null alleles was decreased to $3.6 \%$. To determine whether $\mathrm{CHD}^{+}$patients displayed a frequency distribution of apo(a) isoform size which resembled that in $\mathrm{CHD}^{-}$ patients, plasma samples from each individual were subjected to immunoblot analysis. Compared to acrylamide gels, the agarose-gel system can detect a larger number of apo(a) isoforms [23]. It was necessary therefore to develop a nomenclature distinct from that of Utermann [6], as the latter discriminates be- 
Table 1. Clinical features in NIDDM patients with $\left(\mathrm{CHD}^{+}\right.$ group) or without $\left(\mathrm{CHD}^{-}\right.$group) coronary heart disease

\begin{tabular}{|c|c|c|c|}
\hline & $\begin{array}{l}\mathrm{CHD}^{+} \text {group } \\
n=71\end{array}$ & $\begin{array}{l}\mathrm{CHD}^{-} \text {group } \\
n=67\end{array}$ & $p$-value \\
\hline Sex (male/female) & $59 / 12$ & $48 / 19$ & $\mathrm{NS}^{\mathrm{a}}$ \\
\hline Age (years) & $60.3 \pm 8.5$ & $57.9 \pm 7.7$ & $\mathrm{NS}^{\mathrm{b}}$ \\
\hline Body mass index $\left(\mathrm{kg} / \mathrm{m}^{2}\right)$ & $27.7 \pm 3.8$ & $28.5 \pm 5.0$ & $\mathrm{NS}^{\mathrm{b}}$ \\
\hline $\begin{array}{l}\text { Diabetes duration } \\
\text { (years) }\end{array}$ & $13.1 \pm 8.1$ & $11.5 \pm 7.8$ & $\mathrm{NS}^{\mathrm{b}}$ \\
\hline $\begin{array}{l}\text { Treatment of diabetes } \\
\text { mellitus (insulin/oral } \\
\text { treatment/diet) }(n)\end{array}$ & $30 / 29 / 12$ & $16 / 42 / 9$ & $0.031^{\mathrm{a}}$ \\
\hline Hypertension $(n)$ & 40 & 27 & $N S^{\mathrm{a}}$ \\
\hline $\begin{array}{l}\text { Family history of coro- } \\
\text { nary heart disease }(n)\end{array}$ & 15 & 13 & $N S^{a}$ \\
\hline $\begin{array}{l}\text { Smokers (nil/ex/ } \\
\text { active) }(n)\end{array}$ & $23 / 38 / 10$ & $26 / 24 / 17$ & $N S^{a}$ \\
\hline $\begin{array}{l}\text { Systolic blood } \\
\text { pressure (mmHg) }\end{array}$ & $150.3 \pm 23.9$ & $150.8 \pm 17.5$ & $\mathrm{NS}^{\mathrm{b}}$ \\
\hline $\begin{array}{l}\text { Diastolic blood } \\
\text { pressure }(\mathrm{mm} \mathrm{Hg})\end{array}$ & $88.2 \pm 11.7$ & $92.7 \pm 12.6$ & $<0.03^{b}$ \\
\hline $\begin{array}{l}\text { Anti-hypertensive } \\
\text { treatment }(n)\end{array}$ & 67 & 40 & $0.0001^{\mathrm{a}}$ \\
\hline
\end{tabular}

Values are mean \pm SD. ${ }^{a}$ chi-square test, ${ }^{b}$ analysis of variance

Table 2. Biological data and plasma lipid levels in NIDDM patients with $\left(\mathrm{CHD}^{+}\right.$group) or without $\left(\mathrm{CHD}^{-}\right.$group) coronary heart disease

\begin{tabular}{lccc}
\hline & $\begin{array}{l}\text { CHD } \\
n=71\end{array}$ & $\begin{array}{l}\mathrm{CHD}^{-} \text {group } \\
n=67\end{array}$ & $p$-value \\
\hline $\begin{array}{l}\text { Glycated haemo- } \\
\text { globin }(\%)\end{array}$ & $8.4 \pm 1.9$ & $7.6 \pm 1.6$ & $<0.01^{\mathrm{a}}$ \\
$\begin{array}{l}\text { Creatinine }(\mu \mathrm{mol} / \mathrm{l}) \\
95.9 \pm 15.0\end{array}$ & $87.0 \pm 12.7$ & $<0.01^{\mathrm{a}}$ \\
$\begin{array}{l}\text { Micro- or macro- } \\
\text { albuminuria }(n)\end{array}$ & 32 & 11 & $0.0006^{\mathrm{b}}$ \\
$\begin{array}{l}\text { Urinary albumin } \\
\text { excretion rate }\end{array}$ & $30(5-4620)$ & $9(5-700)$ & $<0.01^{\mathrm{a}}$ \\
(mg/24 h) & & & \\
$\begin{array}{l}\text { Plasma lipids } \\
\text { (mmol/l): }\end{array}$ & & & \\
Total-cholesterol & $6.0 \pm 1.0$ & $5.5 \pm 1.2$ & $<0.02^{\mathrm{a}}$ \\
HDL-cholesterol & $1.21 \pm 0.38$ & $1.17 \pm 0.30$ & $\mathrm{NS}^{\mathrm{a}}$ \\
Triglycerides & $2.1 \pm 1.5$ & $1.9 \pm 1.2$ & $\mathrm{NS}^{\mathrm{a}}$ \\
ApoA1 $(\mathrm{g} / \mathrm{l})$ & $1.52 \pm 0.3$ & $1.50 \pm 0.2$ & $\mathrm{NS}^{\mathrm{a}}$ \\
ApoB (g/1) & $1.41 \pm 0.3$ & $1.25 \pm 0.3$ & $<0.01^{\mathrm{a}}$ \\
\hline
\end{tabular}

${ }^{a}$ Analysis of variance with $\log _{10}$ transformation for triglycerides and albuminuria, ${ }^{b}$ chi-square test, ${ }^{\mathrm{c}}$ median (range)

tween only six different isoforms. We attributed an arbitrary molecular mass to the four isoforms present in our standard $(\mathrm{F}$, $\mathrm{S} 1, \mathrm{~S} 2$ and S3). Since apo B100 (550 kDa) migrated to a position exactly intermediate between that of the $\mathrm{F}$ and $\mathrm{S} 1$ isoforms, we used values of $500,600,700$ and $800 \mathrm{kDa}$ for $\mathrm{F}, \mathrm{S} 1, \mathrm{~S} 2$ and $\mathrm{S} 3$, re- spectively. The apparent molecular mass of the various isoforms detected in patients, plasma was then calculated according to their migration with respect to the standard. For the purpose of this study, we decided to combine apo(a) phenotypes into two groups as proposed by Sandholzer et al. [11]. The first group comprised all subjects who displayed a phenotype with at least one small isoform, i.e. $\leq 700 \mathrm{kDa}$, a size which corresponds approximately to the $\mathrm{S} 2$ isoform in Utermann's classification; such isoforms are generally associated with high $L p(a)$ levels in a normal population [6]. The second group included all subjects who exhibited one or two apo(a) isoforms larger than $700 \mathrm{kDa}$, together with those displaying the null phenotype.

\section{Statistical analysis}

Data are expressed as mean $\pm \mathrm{SD}$, unless stated otherwise. A $p$ value of 0.05 or less was considered as significant. Serum triglycerides, $L p(a)$ values, apo(a) phenotypes and urinary albumin excretion rate were logarithmically transformed before inclusion in all statistical tests. One way analysis of variance was conducted for continuous variables. Qualitative traits were analysed by contingency table chi-squared. For correlation analysis, Pearson's correlation coefficient was calculated. The potential contribution of apo(a) phenotype to the variance in $\mathrm{Lp}$ (a) levels in both $\mathrm{CHD}^{+}$ patients and $\mathrm{CHD}^{-}$patients was estimated by the $R^{2}$ parameter obtained from analysis of variance. As a measure of the possible association between clinical and biological data and coronary heart disease, the odds ratio and $95 \%$ confidence intervals were calculated. Simultaneous adjustments for qualitative and quantitative variables were carried out, using a logistic regression model, in which only variables showing a significant association with coronary heart disease in univariate analysis $(p \leq 0.05)$ were introduced. For all calculations, the BMDP Statistical Software (University of California Press, Berkeley, Calif., USA) was used.

\section{Results}

The clinical characteristics of NIDDM patients with or without coronary heart disease are shown in Table 1. The $\mathrm{CHD}^{+}$group included significantly more insulintreated patients than the $\mathrm{CHD}^{-}$group. NIDDM patients with coronary heart disease displayed significantly lower diastolic blood pressure than the $\mathrm{CHD}^{-}$ group, although systolic blood pressure did not differ between the groups. The higher frequency of antihypertensive treatment in $\mathrm{CHD}^{+}$patients, introduced principally for secondary cardiovascular prevention, may explain this unexpected result. Indeed, betablockers $(49 \%)$ and calcium antagonists $(67 \%)$ were mainly used in the $\mathrm{CHD}^{+}$group.

The biological and lipid profiles of our patient groups are shown in Table 2. Glycated haemoglobin, serum creatinine, total cholesterol and apoB were significantly higher in the $\mathrm{CHD}^{+}$group. In addition, the prevalence of micro- or macroalbuminuria was higher in the $\mathrm{CHD}^{+}$group $(45.1 \%$ vs $16.4 \% ; p=0.0006)$.

The overall frequencies of elevated $L p(a)$ levels did not differ significantly between the sub-groups of patients and controls. Therefore the subsequent analyses were performed on all study subjects. Plasma Lp(a) concentrations and the frequencies of apo(a) phenotypes in 
Table 3. $\mathrm{Lp}(\mathrm{a})$ concentrations and frequencies of apo(a) phenotypes in NIDDM patients with $\left(\mathrm{CHD}^{+}\right.$group) or without $\left(\mathrm{CHD}^{-}\right.$group) coronary heart disease

\begin{tabular}{|c|c|c|c|c|c|}
\hline & \multicolumn{2}{|c|}{$\begin{array}{l}\mathrm{CHD}^{+} \text {group } \\
n=71\end{array}$} & \multicolumn{2}{|c|}{$\begin{array}{l}\text { CHD } \\
n=67\end{array}$} & $p$-value \\
\hline $\operatorname{Lp}(a)^{a}(g / 1)$ & \multicolumn{2}{|c|}{$\begin{array}{l}0.29 \pm 0.41(0.11) \\
(0.20-0.39)\end{array}$} & \multicolumn{3}{|c|}{$\begin{array}{l}0.18 \pm 0.28(0.10) 0.19^{b} \\
(0.11-0.25)\end{array}$} \\
\hline $\begin{array}{l}\mathrm{Lp}(\mathrm{a}) \geq 0.3 \mathrm{~g} / \mathrm{l} \\
(\text { n) }(\%)\end{array}$ & \multicolumn{2}{|c|}{$24(33.8)$} & \multicolumn{2}{|c|}{$9(13.4)$} & $0.005^{c}$ \\
\hline $\begin{array}{l}\text { Phenotype class } \\
(\mathrm{kDa})\end{array}$ & $\%$ & $n$ & $\%$ & $n$ & $0.043^{c}$ \\
\hline$\leq 500$ & 0 & 0 & 1.49 & 1 & - \\
\hline$\leq 600$ & 1.22 & 1 & 2.90 & 2 & - \\
\hline$\leq 700$ & 28.05 & 20 & 11.59 & 8 & - \\
\hline$\leq 800$ & 21.95 & 16 & 31.88 & 21 & - \\
\hline$\leq 900$ & 28.05 & 18 & 42.03 & 28 & - \\
\hline$\leq 1000$ & 15.85 & 12 & 8.70 & 6 & - \\
\hline Null type & 5.63 & 4 & 1.49 & 1 & - \\
\hline
\end{tabular}

${ }^{a}$ Mean \pm SD (median) $\left(95 \%\right.$ confidence interval) ${ }^{b}$ analysis of variance after $\log _{10}$ transformation, ${ }^{c}$ chi-square test

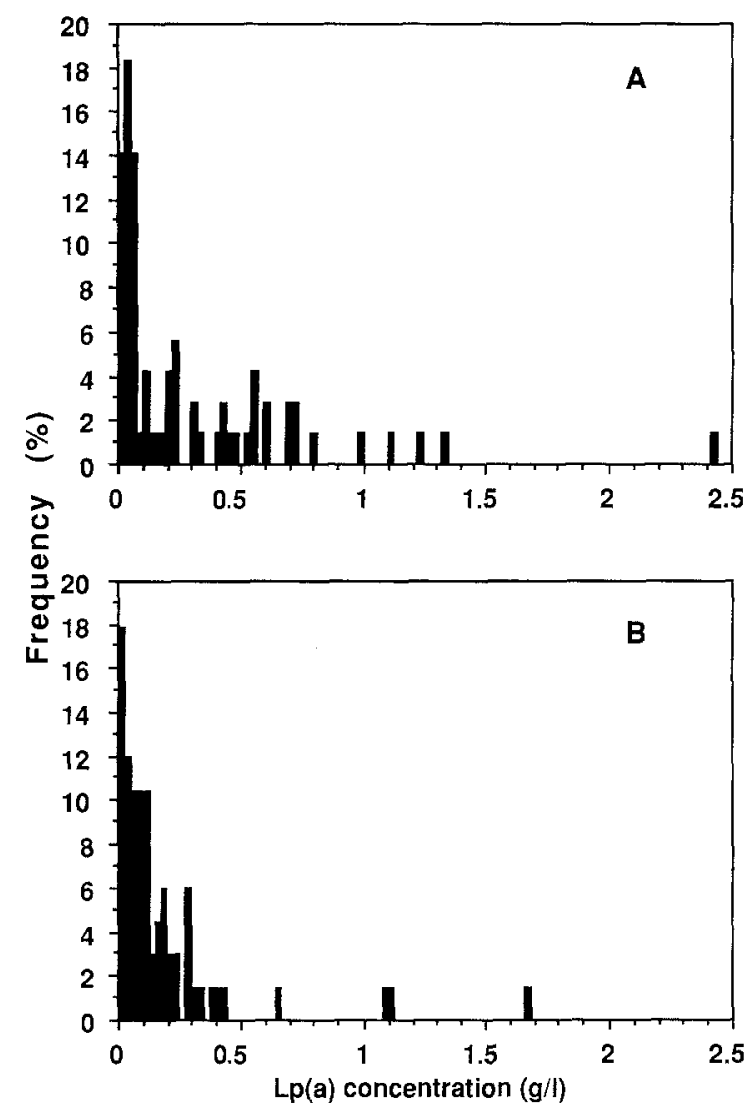

Fig. 1A, B. Histograms showing the distribution of $L p(a)$ concentrations in NIDDM patients with $(\mathbf{A})$ and without $(\mathbf{B})$ coronary heart disease

$\mathrm{CHD}^{+}$and $\mathrm{CHD}^{-}$patients are shown in Table 3. There was a positive trend towards higher $L p(a)$ concentrations in $\mathrm{CHD}^{+}$patients compared to $\mathrm{CHD}^{-}$patients; indeed, mean $\mathrm{Lp}$ (a) values were $50 \%$ higher in patients who have coronary heart disease. Patients with elevated
$\mathrm{Lp}(\mathrm{a})$ concentrations (defined as those $>0.3 \mathrm{~g} / \mathrm{l}$ ) were significantly more frequent in $\mathrm{CHD}^{+}$patients than in CHD patients ( $p=0.005$, Fig. 1).

Hypolipidaemic agents had been prescribed in 23 patients $(32.4 \%)$ in the $\mathrm{CHD}^{+}$group and in 10 patients $(14.9 \%)$ in the $\mathrm{CHD}^{-}$group $(p=0.016)$. In the $\mathrm{CHD}^{+}$group, fibrates and HMGCoA-reductase inhibitors were being taken by 18 and 5 patients, respectively. In the $\mathrm{CHD}^{-}$group, fibrates and HMGCoA-reductase inhibitors were being taken by 6 and 4 patients, respectively. These two groups of pharmacological agents have not definitively been shown to modify $\mathrm{Lp}$ (a) levels but may have significantly influenced other plasma lipid parameters. Lp(a) concentration was not correlated with other clinical and biological parameters in our patient groups when considered either together or separately, with the exception of apoB in $\mathrm{CHD}^{-}$patients $(r=0.29, p=0.03)$.

The overall size range of apo(a) isoforms (480 to $980 \mathrm{kDa}$ ) was similar in both patient groups studied. Double-band phenotypes were present in 45 patients $(32.6 \%)$, and single-band phenotypes in 88 patients $(63.8 \%)$; the null type was observed in 5 patients $(3.6 \%)$. The frequency of apo(a) isoforms whose size was below $700 \mathrm{kDa}$ was not significantly greater in $\mathrm{CHD}^{+}$patients as compared to $\mathrm{CHD}^{-}$patients $(p=$ 0.067 ), but a trend to ward a predominance of isoforms of low molecular mass was observed in the $\mathrm{CHD}^{+}$ group $(29.6 \%)$ as compared to the $\mathrm{CHD}^{-}$group $(16.4 \%)$. The overall distribution of apo(a) phenotypes was however significantly displaced towards low molecular mass isoforms in the $\mathrm{CHD}^{+}$group ( $p=0.043$; Table 3 ). In both populations, apo(a) isoforms were significantly associated with $\mathrm{Lp}(\mathrm{a})$ levels $\left(r=-0.58, p=0.0001\right.$ for $\mathrm{CHD}^{+}$and $r=-0.34, p=$ 0.0049 for $\mathrm{CHD}^{-}$), though mean $\mathrm{Lp}$ (a) levels and the frequency distribution of apo(a) phenotypes were distinct between the two groups. Thus, the inverse relation observed by Utermann et al. [6] between the size of the apo(a) isoform and $\mathrm{Lp}(\mathrm{a})$ concentration in plasma also exists in our population of diabetic patients, either with or without coronary heart disease. We subsequently estimated the contribution of apo(a) phenotypes to the inter-individual variation in $\mathrm{Lp}(\mathrm{a})$ concentrations by $R^{2}$ from analysis of variance. The fraction of the variance in $L p(a)$ levels which was explained by apo(a) isoforms was two-fold larger in the $\mathrm{CHD}^{+}$group as compared to the $\mathrm{CHD}^{-}$group ( 0.28 and 0.15 , respectively).

Univariate analyses, with cardiovascular status as the categorical dependent variable, were performed to evaluate a possible association of clinical and biological parameters with the risk of coronary heart disease (Table 4). Elevated $L p(a)$ values were significantly associated with coronary heart disease, giving an odds ratio of 3.1. Although not statistically significant $(p=0.067)$, a trend toward an association between apo(a) phenotypes of low molecular mass and the risk of coronary heart disease was observed. A significant 
Table 4. Crude odds ratio of coronary heart disease in relation to cardiovascular risk factors

\begin{tabular}{|c|c|c|c|}
\hline & $\begin{array}{l}\text { Odds } \\
\text { ratio }\end{array}$ & $\begin{array}{l}95 \% \text { confidence } \\
\text { interval }\end{array}$ & $p$-value \\
\hline $\mathrm{Lp}(\mathrm{a})(\geq 0.3 \mathrm{~g} / \mathrm{l})$ & 3.10 & $1.31-7.34$ & 0.010 \\
\hline \multicolumn{4}{|l|}{ Apo(a) phenotypes } \\
\hline$\leq 700 \mathrm{kDa}$ & 2.14 & $0.95-4.82$ & 0.067 \\
\hline Age (years) & 1.04 & $0.99-1.08$ & 0.116 \\
\hline Sex (male/female) & 2.01 & $0.87-4.67$ & 0.104 \\
\hline Smokers (yes/no) & 1.42 & $0.70-2.87$ & 0.330 \\
\hline $\begin{array}{l}\text { Micro- and macro- } \\
\text { albuminuria (yes/no) }\end{array}$ & \multicolumn{3}{|c|}{ Micro- and macro- } \\
\hline $\mathrm{HbA}_{1 \mathrm{c}}(\%)$ & 1.34 & $1.09-1.66$ & 0.007 \\
\hline Creatinine $(\mu \mathrm{mmol} / 1)$ & 1.05 & $1.02-1.08$ & $<0.001$ \\
\hline \multicolumn{4}{|l|}{ Total cholesterol } \\
\hline$(\mathrm{mmol} / \mathrm{l})$ & $\begin{array}{l}1.68 \\
671\end{array}$ & $\begin{array}{l}1.19-2.39 \\
1.93-23.37\end{array}$ & $\begin{array}{l}0.004 \\
0.003\end{array}$ \\
\hline $\operatorname{ApoB}(g / 1)$ & 6.71 & & \\
\hline
\end{tabular}

Table 5. Logistic regression analysis of cardiovascular risk factors associated with coronary heart disease in univariate analysis

\begin{tabular}{llll}
\hline & $\begin{array}{l}\text { Odds } \\
\text { ratio }\end{array}$ & $\begin{array}{l}95 \% \text { confidence } \\
\text { interval }\end{array}$ & $p$-value \\
\hline Lp(a) $(\geq 0.3 \mathrm{~g} / \mathrm{l})$ & 3.48 & $1.19-10.22$ & 0.0233 \\
$\begin{array}{l}\text { Micro- and macro- } \\
\text { albuminuria }\end{array}$ & 3.37 & $1.18-9.63$ & 0.0230 \\
Creatinine & 1.05 & $1.01-1.09$ & 0.0115 \\
ApoB & 6.54 & $0.62-68.76$ & 0.1178 \\
Insulin treatment & 0.68 & $0.40-1.15$ & 0.1524 \\
Glycated haemoglobin & 1.17 & $0.87-1.58$ & 0.3085 \\
Total cholesterol & 0.93 & $0.48-1.79$ & 0.8279 \\
\hline
\end{tabular}

association was observed between creatinine, micro- or macroalbuminuria, $\mathrm{HbA}_{1 \mathrm{c}}$ and coronary heart disease. Total cholesterol and apoB were also significantly associated with coronary heart disease. The other lipid and apolipoprotein parameters (triglycerides, HDL-cholesterol and apoA1) did not show any significant association with coronary heart disease.

According to the univariate analyses, high $\mathrm{Lp}$ (a) levels were found to be a risk factor for coronary heart disease in this NIDDM population. A multiple logistic regression analysis was performed (Table 5), introducing the cardiovascular risk factors for coronary heart disease that were identified in previous analyses ( $p$ value $<5 \%$ ). In our NIDDM population, high Lp(a) levels appeared to be an independent cardiovascular risk factor (odds ratio 3.48, $p=0.0233$ ). High $\mathrm{Lp}(\mathrm{a})$ levels contribute to increased risk of coronary heart disease independently of micro- or macroalbuminuria and creatinine; the latter parameters which were also independently associated with coronary heart disease in this study. It must be emphasized that the association between high $\mathrm{Lp}(\mathrm{a})$ levels and coronary heart disease was significant in NIDDM patients without micro- and macroalbuminuria (odds ratio $3.97, p<0.01$ ) but not in the sub-group with diabetic nephropathy (odds ratio 1.76, NS) (data not shown).

\section{Discussion}

In this case-control study, we have evaluated the relation between Lp(a) levels, apo(a) phenotypes and coronary heart disease in a Caucasian population of NIDDM patients. We found a significant and independent association between elevated $L p(a)$ levels and the presence of coronary heart disease in these patients when a plasma $L p($ a) level of $0.3 \mathrm{~g} / 1$ was used as the cut-off; this level was defined as the threshold for high cardiovascular risk [25] and correspond to the $75^{\text {th }}$ percentile in our laboratory (data not shown). This finding was not a consequence of diabetic nephropathy as significant differences were observed when patients without nephropathy were examined separately. Conversely, differences were not significant when patients with micro- or macroalbuminuria were examined, although fewer patients were included in this group. We also observed a trend toward high $\mathrm{Lp}(\mathrm{a})$ concentrations in $\mathrm{CHD}^{+}$patients, in agreement with other studies involving non-diabetic populations $[9,25,26]$. The lack of significance which we observed may be due to the relatively small size of the study population and could also be due to its cross-sectional design. This latter point may be important, because elevated $\mathrm{Lp}$ (a) concentrations could lead to premature cardiovascular death.

The use of lipid-lowering therapy was not considered as an exclusion criterion. The impact of the different lipid-lowering drug therapies may thus have contributed to the negative results concerning the association between triglycerides, HDL-cholesterol and coronary heart disease in this study. In addition, the relatively small size of the population may also be a factor. With the exception of nicotinic acid [27], no hypolipidaemic agent has as yet been proven to consistently modify circulating Lp(a) levels. Similarly, anti-hypertensive treatment, such as beta-blockers which are known to modify plasma lipid levels, was more frequent in the $\mathrm{CHD}^{+}$group. To our knowledge, a relationship between anti-hypertensive treatment and $\mathrm{Lp}$ (a) concentrations has not been firmly established; nonetheless, we cannot exclude a possible influence of anti-hypertensive treatment on L $p(a)$ levels. In particular, angiotensin-converting enzyme may improve lipid abnormalities in NIDDM hypertensive patients [28]. In our study, the percentage of patients treated with angiotensin-converting enzyme inhibitor was significantly higher in the $\mathrm{CHD}^{-}$group than in $\mathrm{CHD}^{+}$ group ( $68 \%$ vs $33 \%, p<0.01$, data no shown).

Two studies in NIDDM patients did not detect an association between Lp(a) levels and coronary heart disease $[14,15]$. Survival bias might however explain these negative results, as well as misclassification of NIDDM patients with or without coronary heart disease. Clinical examination and/or resting electrocardiography provide low sensitivity and specificity in such patients. Some of the presumed diabetic subjects without coronary heart disease may have had clinically undetected 
coronary artery disease which frequently occurs in diabetic patients [18]. In the present study, we therefore used both non-invasive tests and coronary angiography to extensively evaluate coronary artery disease.

We found that the global distribution of apo(a) phenotypes differed significantly between the $\mathrm{CHD}^{+}$ and $\mathrm{CHD}^{-}$groups. The frequency of apo(a) phenotypes $700 \mathrm{kDa}$ or less was two-fold higher in $\mathrm{CHD}^{+} \mathrm{pa}^{-}$ tients compared to that in $\mathrm{CHD}^{-}$patients, but did not reach statistical significance. When the distribution of apo(a) phenotypes in NIDDM patients was compared with that in non-diabetic control subjects by Csaszar et al. [13], no significant difference was shown, suggesting that apo(a) phenotype and incidence of diabetes are independent. Nonetheless, our present results suggest that $L p(a)$ concentrations in NIDDM patients are genetically controlled as in non-diabetic Caucasians, and consequently, could potentially contribute to coronary heart disease. The contribution of apo(a) phenotypes to $\mathrm{Lp}(\mathrm{a})$ levels was greater in $\mathrm{CHD}^{+}$patients than in the $\mathrm{CHD}^{-}$group. A similar observation was previously reported in normal subjects by Sandholzer et al. [11]. In addition, size of apo(a) isoform may also be a contributing factor to its cardiovascular effects $[11,29]$. Other genetic factors might also influence $\mathrm{Lp}(\mathrm{a})$ concentrations. Indeed, a recent study [30] has shown that the apo(a) gene is more polymorphic in sequence than previously thought based on the number of kringle 4 repeats. However, a variety of non-genetic factors has also been shown to affect $L p(a)$ concentrations; some of which are associated with increased coronary heart disease prevalence such as menopause [31] or end-stage renal disease [32]. We previously demonstrated [21] that $\mathrm{Lp}(\mathrm{a})$ levels are elevated in end-stage renal disease, but we did not detect any association with diabetes in this population. Consequently, diabetic patients who had renal insufficiency were excluded from the present study. Given this restriction, no correlation was observed between albuminuria and $\mathrm{Lp}$ (a) concentrations. Data on the possible association between these two variables are inconclusive in NIDDM, as both positive [33] and negative findings have been reported $[34,35]$.

Other classic cardiovascular risk factors were also associated with coronary heart disease in this study, and these include micro- or macroalbuminuria or both, which are well established as independent cardiovascular risk factors in NIDDM [36]. Plasma total cholesterol and apoB levels were also significantly associated with coronary heart disease in our patients, despite the more frequent use of hypolipidaemic treatment in the $\mathrm{CHD}^{+}$group.

In conclusion, our study has demonstrated a positive and independent association between elevated $\mathrm{Lp}(\mathrm{a})$ levels and coronary heart disease in NIDDM Caucasian patients. Furthermore, the observed difference in the distribution of apo(a) phenotypes between $\mathrm{CHD}^{-}$and $\mathrm{CHD}^{+}$patients is consistent with suggestions that the apo(a) gene locus influences the risk for coronary heart disease in diabetic patients through its effect on $L p(a)$ levels [11]. Diabeticnephropathy was not a contributory factor to the increased $\mathrm{Lp}(\mathrm{a})$ levels in NIDDM patients. Large, long-term, prospective studies are now required to eliminate survival bias and to assess whether high $\mathrm{Lp}$ (a) levels and apo(a) phenotypes are associated with the incidence of coronary heart disease and other vascular complications in NIDDM patients.

Acknowledgements. This study was supported by grants from the Fonds National Suisse de la Recherche Scientifique (Dr J. Ruiz, No. 3, 07.00).

\section{References}

1. Stamler J, Vaccaro O, Neaton JD, Wentworth D, Group MR (1993) Diabetes, other risk factors, and 12-yr cardiovascular mortality for men screened in the Multiple Risk Factor Intervention Trial. Diabetes Care 16: 434-444

2. Assmann G, Schutle H (1988) The Prospective Cardiovascular Münster (PROCAM) Study: prevalence of hyperlipidemia in persons with hypertension and/or diabetes mellitus and the relationship to coronary heart disease. Am Heart $\mathrm{J}$ 116: $1713-1724$

3. Kannel WB, Mc Gee DL (1979) Diabetes and cardiovascular risk factors. The Framingham study. Circulation 59: 8-13

4. Mc Lean JW, Tomlinson JE, Kuang WJ, Eaton DL, Chen EY, Fless GM (1987) cDNA sequence of human apolipoprotein(a) is homologous to plasminogen. Nature 330: 132-137

5. Lackner C, Boerwinkle E, Leffert CC, Rahmig T, Hobbs HH (1991) Molecular basis of apolipoprotein(a) isoform size heterogeneity as revealed by pulse-field gel electrophoresis. J Clin Invest 87: 2153-2161

6. Utermann G, Menzel HJ, Kraft HG, Duba HC, Kemmler HG, Seitz C (1987) Lp(a) glycoprotein phenotypes: inheritance and relation to $\mathrm{Lp}(\mathrm{a})$-lipoprotein concentrations in plasma. J Clin Invest 80: 458-465

7. Boerwinkle E, Menzel HJ, Kraft HG, Utermann G (1989) Genetics of the quantitative Lp(a) lipoprotein trait. Contribution of $\mathrm{Lp}(\mathrm{a})$ glycoprotein phenotypes to normal lipid values. Hum Genet 82: 73-78

8. Scanu AM, Fless GM (1990) Lipoprotein(a). Heterogeneity and biological relevance. J Clin Invest 85: 1709-1715

9. Genest J, Jenner JL, McNamara JR et al. (1991) Prevalence of lipoprotein(a) (Lp(a)) excess in coronary artery disease. Am J Cardiol 67: 1039-1045

10. Sandholzer C, Boerwinkle E, Saha N, Tong MC, Utermann G (1992) Apolipoprotein(a) phenotype, Lp(a) concentration and plasma lipid levels in relation to coronary heart disease in a Chinese population: evidence for the role of apo(a) gene in coronary heart disease. J Clin Invest 89: 1040-1046

11. Sandholzer C, Saha N, Kark JD et al. (1992) Apo(a) isoforms predict risk for coronary heart disease: a study of six populations. Arterioscler Thromb 12: 1214-1226

12. Haffner SM, Morales PA, Stern MP, Gruber MK (1992) Lp(a) concentrations in NIDDM. Diabetes 41: 1267-1272

13. Császár A, Dieplinger H, Sandholzer C et al. (1993) Plasma lipoprotein(a) concentration and phenotypes in diabetes mellitus. Diabetologia 36: 47-51

14. Niskanen L, Mykkänen L, Karonen SL, Uusitupa M (1993) Apoprotein(a) levels in relation to coronary heart disease and risk factors in type 2 (non-insulin-dependent) diabetes. Cardiovascular Risk Factors 3: 76-81 
15. Heller FG, Jamart J, Honore P et al. (1993) Serum lipoprotein(a) in patients with diabetes mellitus. Diabetes Care 16 : 819-823

16. Velho G, Erlich D, Turpin E et al. (1993) Lipoprotein(a) in diabetic patients and normoglycemic relatives in familial NIDDM. Diabetes Care 16: 742-747

17. Nesto RW, Philipps RT (1986) Asymptomatic myocardial ischemia in diabetic patients. Am J Med 80 [Suppl 4 C]: $40-47$

18. Naka M, Hiramatsu K, Aizawa T et al. (1992) Silent myocardial ischemia in patients with non-insulin-dependent diabetes mellitus as judged by treadmill exercise testing and coronary angiography. Am Heart J 23: 46-52

19. Nesto RW, Philipps RT, Kett KG et al. (1988) Angina and exertional ischemia in diabetic and nondiabetic patients: assessment by exercise thallium scintigraphy. Ann Intern Med 108: $170-175$

20. WHO Study Group (1985) Diabetes mellitus. World Health Organisation, Tech Rep Ser no. 727, Geneva

21. Thillet J, Faucher C, Issad B, Allouache M, Chapman J, Jacobs C (1993) Lipoprotein(a) in patients treated by continuous ambulatory peritoneal dialysis. Am J Kidney Dis 22: 226-232

22. Guo HC, Armstrong VW, Luc G et al. (1989) Characterization of five mouse monoclonal antibodies to apolipoprotein(a) from human $\mathrm{Lp}(\mathrm{a})$ : evidence for weak plasminogen reactivity. J Lipid Res 30: 23-37

23. Kamboh MI, Ferrell RE, Kottke BA (1991) Expressed hypervariable polymorphism of apolipoprotein(a). Am J Hum Genet 49: 1063-1074

24. Bronstein I, Voyta JC, Murphy OJ, Bresnick L, Kricka LJ (1992) Improved chemiluminescent Western blotting procedure. Biotechniques 12: 748-753

25. Dahlén GH, Guyton JR, Attar M, Farmer JA, Kautz JA, Gotto AM (1986) Association of levels of lipoprotein Lp(a), plasma lipids and other lipoproteins with coronary artery disease documented by angiography. Circulation 74: 758-765

26. Cressmann MD, Heyka RJ, Paganini EP, O'Neil J, Skibinski CI, Hoff HF (1992) Lipoprotein(a) is an independent risk factor for cardiovascular disease in hemodialysis patients. Circulation 86: 475-482

27. Carlson LA, Hamsten A, Asplund A (1989) Pronounced lowering of serum levels of lipoprotein $\mathrm{Lp}(\mathrm{a})$ in hyperlipidemic subjects treated with nicotinic acid. J Int Med 226: 271-276

28. Keilani T, Schlueter WA, Levin ML, Batlle DC (1993) Improvement of lipid abnormalities associated with proteinuria using Fosinopril, an angiotensin-converting enzyme inhibitor. Ann Intern Med 118: 246-254

29. Hervio L, Chapman MJ, Thillet J, Loyau S, Anglés-Cano E (1993) Does apolipoprotein(a) heterogeneity influence lipoprotein(a) effects on fibrinolysis? Blood 82: 392-397

30. Cohen JC, Chiesa J, Hobbs H (1993) Sequence polymorphisms in the apolipoprotein(a) gene: evidence of dissociation between apolipoprotein(a) size and plasma lipoprotein(a) levels. J Clin Invest 91: 1630-1636

31. Soma M, Fumagalli R, Paoletti R et al. (1991) Plasma Lp(a) concentration after oestrogen and progestagen in postmenauposal women. Lancet 337:612

32. Parra HJ, Mezdour H, Cachera C, Dracon M, Tacquet A, Fruchart JC (1987) L $p(a)$ lipoprotein in patients with chronic renal failure treated by hemodialysis. Clin Chem 33: 721

33. Jenkins AJ, Steele JS, Janus ED, Santamaria JD, Best JD (1992) Plasma apolipoprotein(a) is increased in type 2 (noninsulin-dependent) diabetic patients with microalbuminuria. Diabetologia 35: 1055-1059

34. Nielsen FS, Voldsgaard AI, Gall MA et al. (1993) Apolipoprotein(a) and cardiovascular disease in type 2 (non-insulindependent) diabetic patients with and without diabetic nephropathy. Diabetologia 36: 438-444

35. Haffner SM, Morales PA, Gruber MK, Hazuda HP, Stern MP (1993) Lack of association of lipids, lipoproteins and Lp(a) with microalbuminuria in NIDDM. Arteriosclerosis 13:205210

36. Mattock MB, Keen H, Viberti GC et al. (1988) Coronary heart disease and urinary albumin excretion rate in type 2 (non-insulin-dependent) diabetic patients. Diabetologia 31: $82-87$ 